\title{
ГИДРОГЕОЛОГИЯ
}

\section{Явление поступления глубинных вод из земных недр и их роль в развитии Земли}

\author{
А.И. Тихонов ${ }^{\mathrm{a}}$, И.С. Копылов \\ ${ }^{\mathrm{a}} \mathrm{OOО}$ «НИИ геологических и геоэкологических проблем» \\ (ООО НИИГиГЭП), 428023, Чебоксары, ул. Академика Королева, 1, оф. 13 \\ E-mail: niigigep@mail.ru \\ ${ }^{\mathrm{b}}$ Естественнонаучный институт Пермского государственного националь- \\ ного исследовательского университета, 614990, Пермь, ул. Генкеля, 4 \\ E-mail: georif@yandex.ru \\ (Статья поступила в редакцию 17 октября 2014 г.)
}

В статье обсуждается явление повсеместного и постоянного поступления в гидросферу Земли из земных недр глубинных вод, характеризующихся повышенным содержанием различных полезных и токсичных химических элементов глубинного происхождения. На основании анализа имеющихся экспериментальных данных предполагается, что глубинные воды являются источником образования и постоянного пополнения океанских вод с практически стабильной минерализацией, химическим и изотопным составом, формирования различных месторождений минеральных вод. Глубинные воды также могут быть причиной образования некондиционных вод в пределах месторождений пресных подземных вод, ухудшающих их экологическое состояние.

Ключевые слова: гидрогеология, глубинные воды, источник, доказательства, изотопь водорода, гелий, уран, плюмы, ядерный реактор.

Согласно принятой в настоящее время в гидрогеологии схеме круговорота воды на Земле, в нем участвуют только процессы испарения со всей поверхности Земли (океаны и суша), атмосферные осадки, поверхностный (реки) и подземный сток (субмаринная разгрузка) в океаны. Следовательно, круговорот воды якобы происходит только в верхней части земной коры и другие внешние источники пополнения гидросферы отсутствуют (рис. 1). На основании этого можно предположить, что гидросфера Земли образовалась только за счет привноса воды из космического пространства и представляет собой метеорные воды, которые почему-то уже не пополняются из космоса. В этом кругово- роте отсутствует возможность поступления воды из глубоких частей планеты, хотя с давних времен известно о поступлении водных паров в процессе вулканических извержений и дегазации Земли.

Между тем в настоящее время уже никого не удивляет, что в образовании гидросферы Земли всегда или по другим данным в определенные периоды времени участвовали и участвуют глубинные процессы Земли, которые «поставляют» или «поставляли» водные пары из глубоких частей Земли в составе различных газов. Сведения о поступлении вод из земных недр и их участии в образовании химического состава океанских вод и рассолов в глубоких водоносных горизонтах можно 
найти, например, в работах В.Ф. Дерпгольца [2], Е.В. Пиннекера [11], Ф. Маркинтайра [6], В. Руби (Rubey), О.Г. Сорохтина [16], А.С. Монина [7] и др. В работах указанных авторов различались только возможные процессы образования и временные интервалы поступления воды из земных глубин. Однако необходимо заметить, что, несмотря на существование предположений о возможности участия в образовании гидросферы Земли кроме метеорной воды и водных паров, поступающих из недр Земли в результате дегазации или высвобождения из минералогического состава горных пород, до сих пор в гидрогеологии отсутствовало общепринятое понятие «глубинные воды», хотя некоторые ученые термин «глубинные воды» использовали при описании вод глубоких горизонтов Земли.

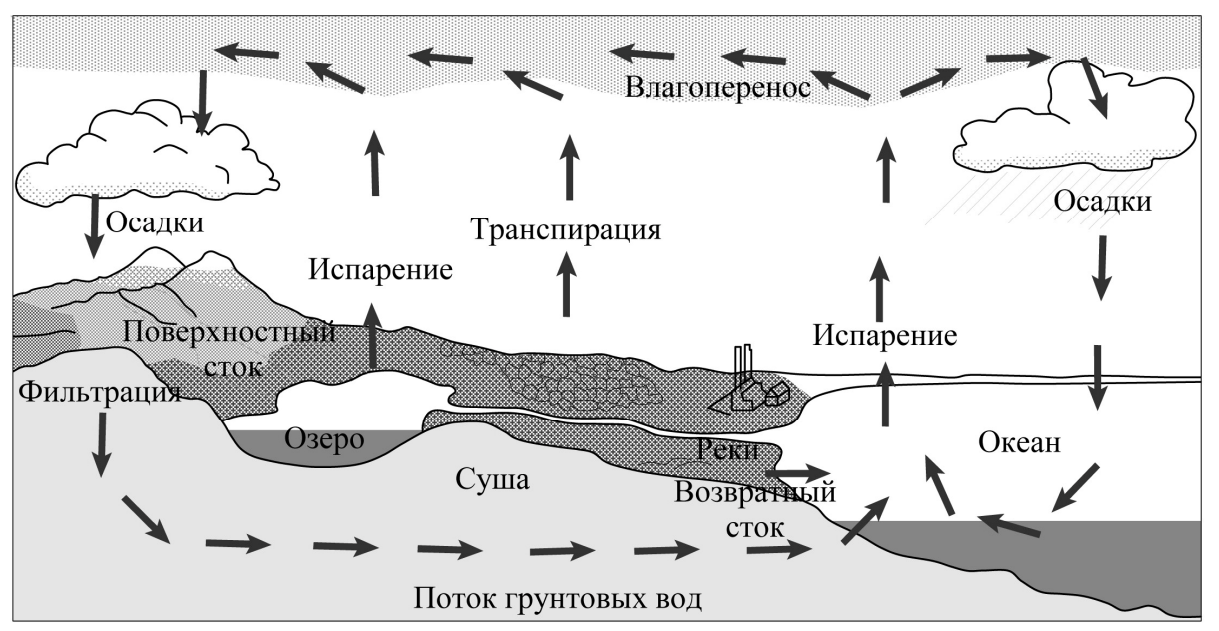

Рис.1. Круговорот воды в природе с точки зрения метеорного происхождения гидросферь

Обоснованность утверждения понятия «глубинные воды» официально подтверждена в наше время научным сообществом [20]. Но в региональной гидрогеологии, к сожалению, и сейчас понятие «глубинные воды» отсутствует. Предполагается, что практически все подземные воды осадочных отложений, в которых в основном проводились поиски и разведка подземных вод питьевого качества и минеральных вод, имеют только инфильтрационное происхождение [3, 8, 11-13]. Такое положение дел в практической гидрогеологии продолжает существенно вредить качеству проведения гидрогеологических работ по разведке и оценке экологического состояния подземных вод. В наше время достоверно установлено [19], что поступающие в разведуемые водоносные горизонты в современную геологическую эпоху глубинные воды нередко содержат токсичные химические элементы, поэтому не соответствуют нормативным требованиям и непригодны для питьевых целей, а их доля в общем балансе водоносного горизонта, как показали балансовые расчеты уран-изотопным методом, иногда может достигать 30-60\%.

Таким образом, мы убеждены, что более обоснованное заключение о присутствии глубинных вод в составе гидросферы Земли и правомерности использования не только термина, но и понятия «глубинные воды» в гидрогеологической науке возможно именно при комплексном рассмотрении этой проблемы не только с точки зрения концентрации дейтерия и трития, входящих непосредственно в молекулы воды, но и изотопного состава растворенных в ней других химических элементов. Учитывая, что природная вода состоит из водорода и кислорода, вполне логично предположить, что именно они могут быть наиболее представительны и наиболее объективные количественные расчеты можно получить при использовании в ка- 
честве индикаторов изотопов водорода и кислорода, т.е. $\delta \mathrm{D}$ и $\delta^{18} \mathrm{O}$. Поэтому рассмотрим этот вопрос более подробно.

Принято считать, что воды мирового океана характеризуются эталонным изотопным составом водорода и кислорода $(\mathrm{SMOW})$, т.е. $\delta \mathrm{D}=0 \%$ и $\delta^{18} \mathrm{O}=0 \%$. Также известно, что по данным большинства исследователей основную массу гидросферы (96-98\%) составляют воды океана. Следовательно, в первом приближении можно принять, что именно океанские воды могут отражать изотопный состав первоисточника гидросферы, т.е. ответить на вопрос, откуда появилась основная масса гидросферы Земли. Сторонники метеорного происхождения гидросферы уверены, что она имеет в основном космическое происхождение. Согласно этой концепции, космическая вода попала на планету в виде частиц льда, входящих в состав космического газопылевого облака в начальный период образования планеты, а также в последующем в результате постоянного падения на планету в виде различных космических тел.

Обратим внимание на некоторые факты. По данным различных ученых, минимальная концентрация дейтерия в «метеорных» водах составляет около - (минус) $200 \%$, а в океанской воде равна $0 \%$ и линия метеорных вод, или «линия Крейга» [29], проходит через точку SMOW со значениями $\delta \mathrm{D}=0 \%$ и $\delta^{18} \mathrm{O}=0 \%$. Однако возникает вопрос: как же объяснить этот парадокс - увеличение концентрации дейтерия от -200 до 0\%о. Этот факт и образование линии метеорных вод можно объяснить только смешением с водами, характеризующимися концентрацией дейтерия с положительными значениями. Действительно, в работе В.И. Ферронского и В.А. Полякова [25] приводятся сведения об обнаружении таких высоких концентраций дейтерия, достигающих значений $+100 \div+300 \%$ в некоторых природных водных источниках, но почему-то умалчиваются причины их образования.

Е.В. Пиннекер [11] также считал, что «предположительно ювенильным водам свойственны повыщенные концентрации тяжельх изотопов водорода и кислоро$\partial a \gg$. Но на его мнение тогда никто не обратил должного внимания и, может быть, это обстоятельство и явилось одним из причин непризнания современной гидрогеологической наукой факта поступления глубинных вод в пределы водоносных горизонтов верхнего гидрогеологического этажа. В.Ф. Дерпгольц еще раньше в работе [2] писал, что «значение ювенильных вод в формировании химического состава природных вод незаслуженно забыто в современной гидрогеологии». Он также считал, что «степень глубинности подземной воды принято определять по изотопному составу кислорода и водорода (утяжеление воды)».

Таким образом, мы видим некоторые противоречивые суждения относительно содержания дейтерия и кислорода-18 в более глубоких горизонтах Земли. В связи с этим считаем необходимым отметить, что в процессе исследований попутных вод Астраханского газоконденсатного месторождения (АГКМ) нами также установлено увеличение концентрации дейтерия [22] с глубиной, что хорошо согласуется с увеличением изотопного сдвига урана - надежного индикатора глубинных вод. Это явление выражается в виде синхронных куполовидных ореолов изменения величины отношения альфаактивности изотопов и концентрации дейтерия (рис. 2). На основе этих данных мы полагаем, что повышенные содержания дейтерия и изотопный сдвиг урана в попутных водах этого месторождения объясняются их поступлением в составе мантийного плюма, образовавшего указанное газоконденсатное месторождение [22]. Мы считаем, что пары глубинных вод образуются из водорода и кислорода, поступающих в составе различных химических элементов и в том числе углеводородных газов в «ядерных» (или мантийных) плюмaх [17] - «продуктах деятельности» ядерного реактора, 


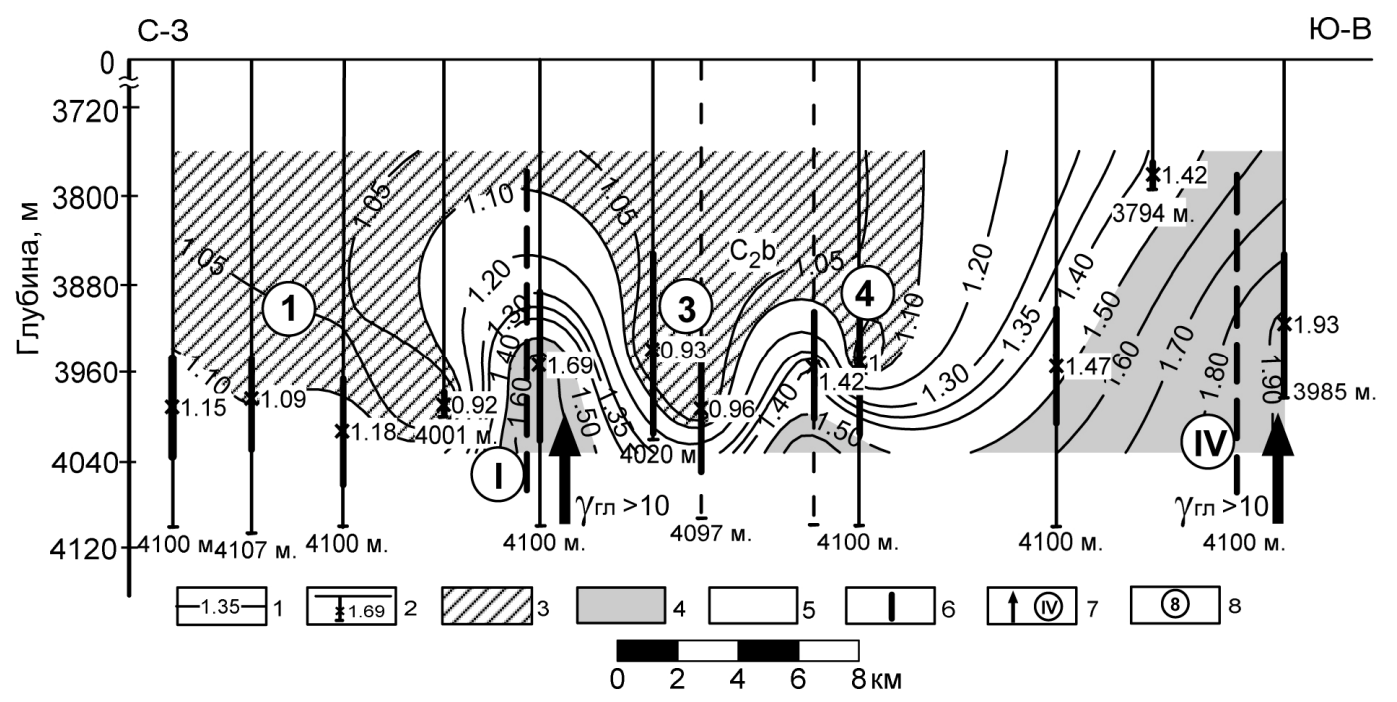

a

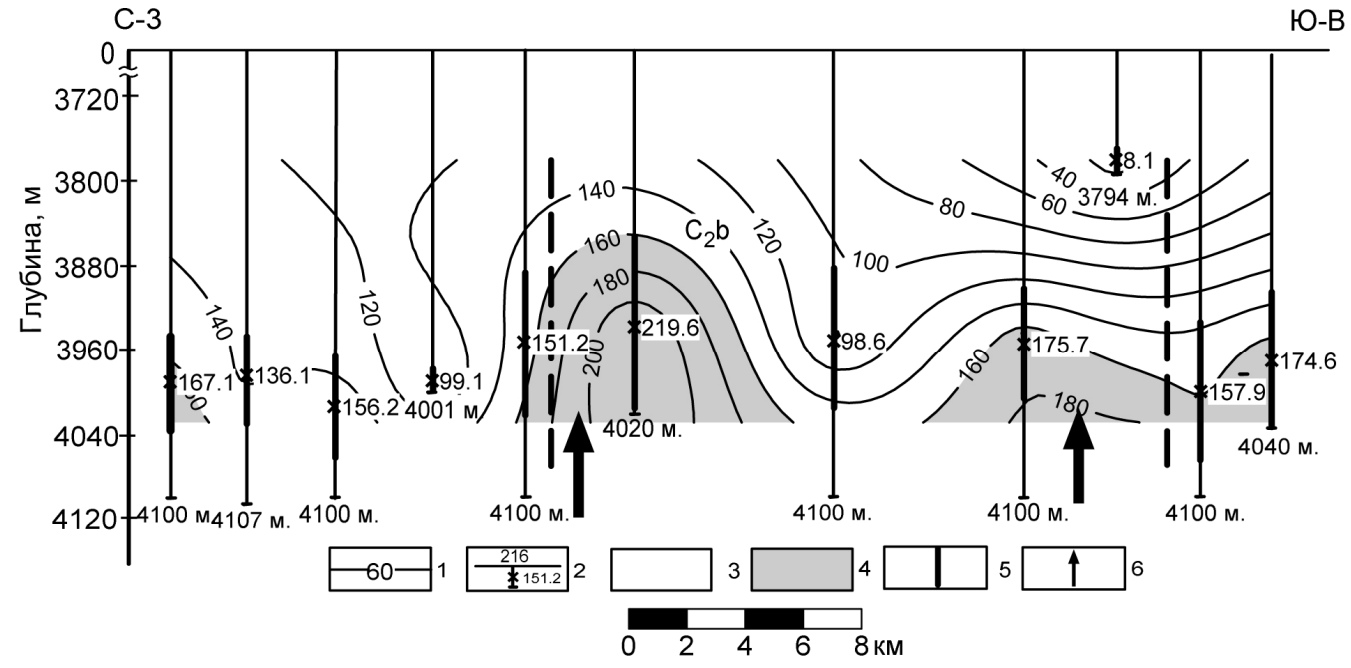

6

Рис. 2. Закономерности изменения величины $\gamma={ }^{234} U{ }^{238} U$ (a) $и$ $\delta D \%$ (б) в попутных водах по разрезу продуктивного горизонта газоконденсатного месторождения. $а$ : 1 - изолиния $\gamma=$ ${ }^{234} U^{238} U ; 2$ - скважина и интервал установки фильтров, иифры - величина $\gamma ; 3-5$ - участки преимущественного распространения пластовых подошвенных и конденсачионных вод седиментачионного происхождения с $\gamma<1.10$ (3), глубинных вод $c \gamma>1.50$ (4) и смешанных вод $c \gamma=$ 1.10-1.50 (5); 6 - тектоническое нарушение; 7 - очаг и номер поступления глубинных вод; 8 номер участка преимущественного распространения пластовых подошвенных и конденсаиионных вод; б: 1 - изолиния $\delta D, \%$; 2 - скважина и интервал установки фильтра, цифры: сверху номер скважины, около фильтра содержание дейтерия (а) и величина $\gamma$ (б); 3,5 - предельы изменения концентрации дейтерия, $\delta D$, \%о: менее 160 (3) и более 160 (4); 5 - тектоническое нарушение; 6-очаги поступления глубинных вод по уран-изотопным данным

источником «питания» которого является сверхтяжелый элемент $\mathrm{X}$ предположительно с порядковым номером 184 [18]. По полученным нами предварительным данным концентрация дейтерия в глубин- ных водах может составлять около $+600 \%$ [22]. Таким образом, наблюдающаяся «нулевая» концентрация дейтерия в океанической воде может быть образована в результате смешения метеорных вод с 
глубинными. Между тем и в опубликованных ранее материалах, по нашему мнению, достаточно фактических данных, свидетельствующих о поступлении в океаны не только дейтерия, но и трития, и легкого изотопа гелия. В опубликованных материалах можно найти ряд примеров, свидетельствующих о поступлении глубинных вод в океаны в районах срединноокеанских хребтов и вулканических островов, образующихся под влиянием мантийных плюмов [3].

В качестве примера рассмотрим некоторые из них.

На рис. 3 приведены схематические карты распределения концентрации дейтерия (\%) и солености в бассейне Атлан- тического океана по данным работы В.И. Ферронского и В.А. Полякова [25]. Мы считаем, что локальные аномалии концентрации дейтерия (до $+10 \%$ ) и минерализации (до 37 г/л) океанских вод в центральных частях Атлантического океана на широте Карибского моря и Бразилии образованы в результате смешения океанских вод с «нулевой» концентрацией дейтерия с глубинными водами, поступающими в составе ядерных (или мантийных?) плюмов [17] в районе Срединноатлантического хребта, т.е. в зоне спрединга океанского дна, и характеризующимися концентрацией дейтерия около $+300-600 \%$ [22].

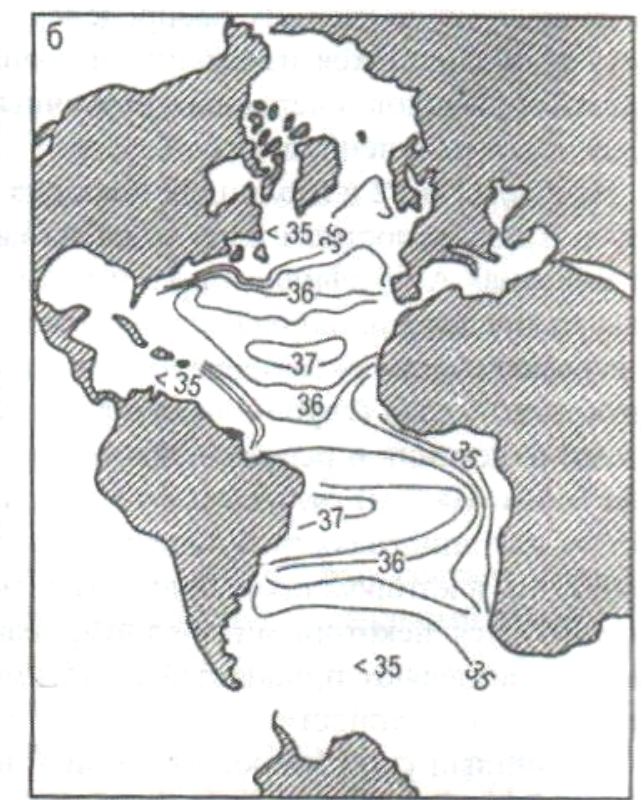

Рис. 3. Распределение концентрации дейтерия (\%) и солености (б) в бассейне Атлантического океана по Redfield, Friedman (1964)

Если принять условно, что содержание дейтерия в глубинных водах составляет около $+300 \%$, то по известной формуле изотопного баланса [26] в аномальной зоне с содержанием дейтерия $+10 \%$ можно определить долю глубинных вод: 3,3\%. Таким образом, этот пример является убедительным аргументом в пользу поступления глубинных вод в районах срединноокеанских хребтов и их участия в образовании океанских вод.

Согласно гипотезе об образовании Земли с природным ядерным реактором в центре [18] наблюдаемый практически повсеместно в глубинных водах легкий изотоп гелия ${ }^{3} \mathrm{He}$ может постоянно генерироваться из трития - продукта резко асимметричного деления сверхтяжелых элементов в ядерном реакторе - и не является первичным «солнечным гелием», якобы имевшимся в составе газопылевого облака и захороненным в ядре планеты неким фантастическим способом, по мнению некоторых исследователей, в момент образования Земли. Между тем в настоящее время имеются исследования других 
ученых, которые позволяют предполагать возможность генерирования легкого изотопа гелия ${ }^{3} \mathrm{He}$ в земном ядре, что в какойто мере согласуется с нашим мнением. Выше мы показали возможность поступления дейтерия из глубинных недр Земли в районах срединно-океанических хребтов, там же могут быть найдены и изотопы не полностью распавшегося трития. Поэтому обратимся к рис. 4, приведенному в работе [24].

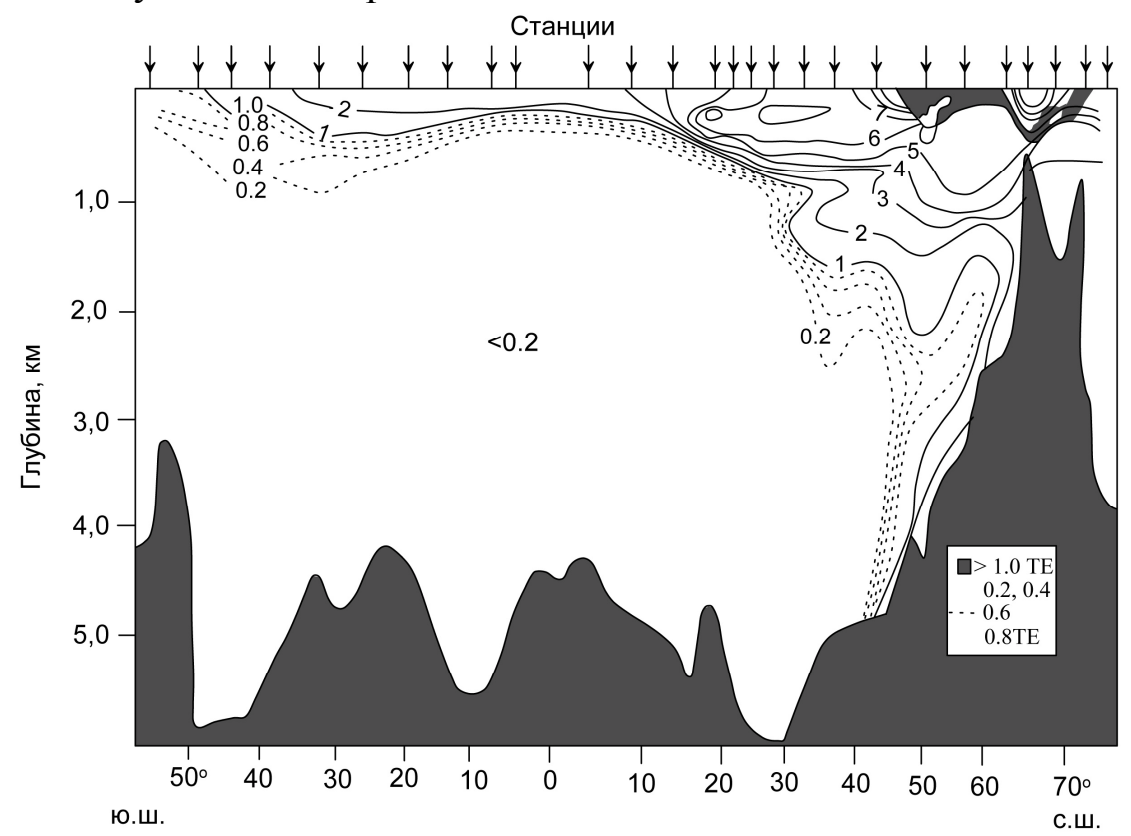

Рис. 4. Меридиональное распределение концентрации трития (TE) в водах Атлантического океана в 1972 г., no Ostlund, Fine (1979)

На рисунке изображены изолинии концентрации трития по разрезу Атлантического океана, которые показывают, что в бо́льшей части океанских вод содержание трития не превышает 1 Т.Е. и только в приповерхностной части местами достигает 2 Т.Е., следовательно, это позволяет предположить, что здесь не может быть локального техногенного загрязнения океанских вод. Вместе с тем можно видеть, что в правой части рисунка в районе $50-70^{\circ}$ с. ш. над наиболее высоким океанским поднятием вулканического происхождения в приповерхностной части океанских вод содержание трития, судя по резкому сгущению изолиний, может достигать 10 T.Е. и более. В то же время изолинии Т.Е. показывают, что изолиния со значением 2 T.Е. опускается вдоль склона океанского поднятия до глубины около 4 км. Мы полагаем, что это явление можно объяснить только поступлением природного трития, а увеличение его концентрации в приповерхностной части - посте- пенным накоплением глубинного не успевающего распадаться трития, поскольку нет никаких оснований допускать возможность образования такой локальной техногенной аномалии трития в океанских просторах именно над этим океанским поднятием, тогда как в округе больше нет подобных аномалий трития. Поэтому мы считаем, что природный тритий образуется при асимметричном делении сверхтяжелых элементов в природном ядерном реакторе Земли в центре планеты. Повидимому, на основе этих данных можно определить также количество ежегодного поступления трития из глубин и объем поступающих в океаны глубинных вод.

Доказательством правомерности предположения об образовании трития по указанному сценарию является также аномальное увеличение концентрации легкого изотопа гелия ${ }^{3} \mathrm{He}$ над другим выступом океанского дна в южной части Атлантического океана, приведенное на рис. 5 из работы [24]. 


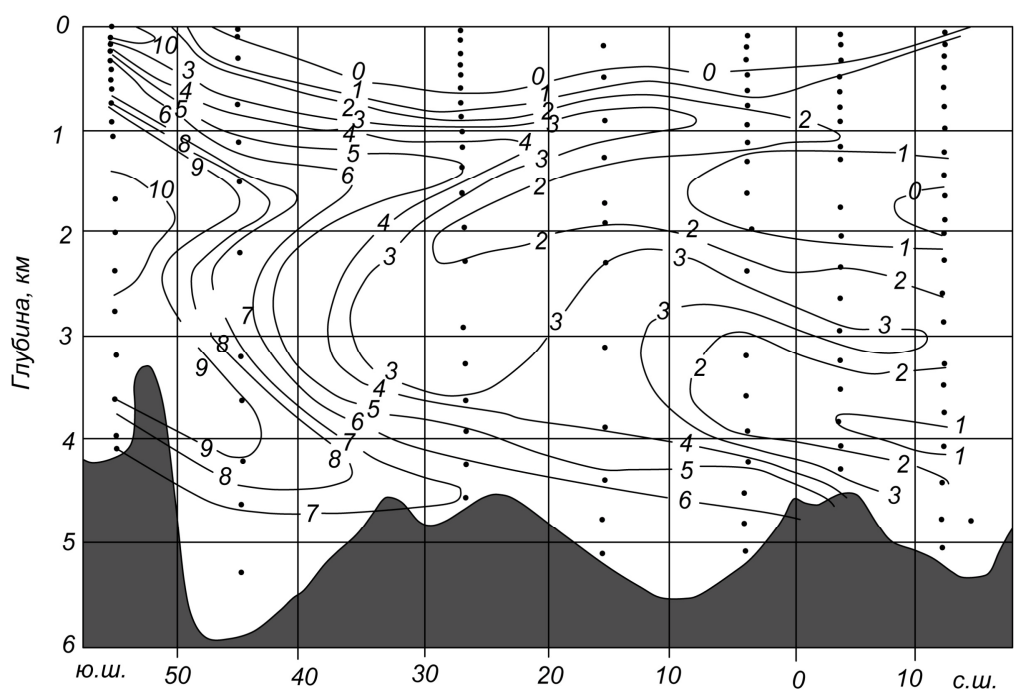

Рис. 5. Меридиональное распределение избытка легкого изотопа гелия $\delta$ (3 Не) в водах Южной Атлантики по Yenkins, Clarke (1976)

Можно заметить постепенное увеличение ${ }^{3} \mathrm{He}$ в основном в придонной части океана, тогда как в приповерхностной части наблюдаются его нулевые концентрации. На рисунке можно видеть, что максимальное содержание ${ }^{3} \mathrm{He}$ наблюдается над выступом дна океана.

Последнее наглядно доказывает поступление изотопа ${ }^{3} \mathrm{He}$ из земных недр с глубинными водами. Еще более наглядно иллюстрирует процесс поступления легкого изотопа гелия ${ }^{3} \mathrm{He}$ с глубинными водами ореол его распространения над вершиной Восточно-Тихоокеанского поднятия, приведенный на рис. 6, на котором изолинии ${ }^{3} \mathrm{He}$ позволяют разглядеть непосредственный выход ореола из вершины поднятия.

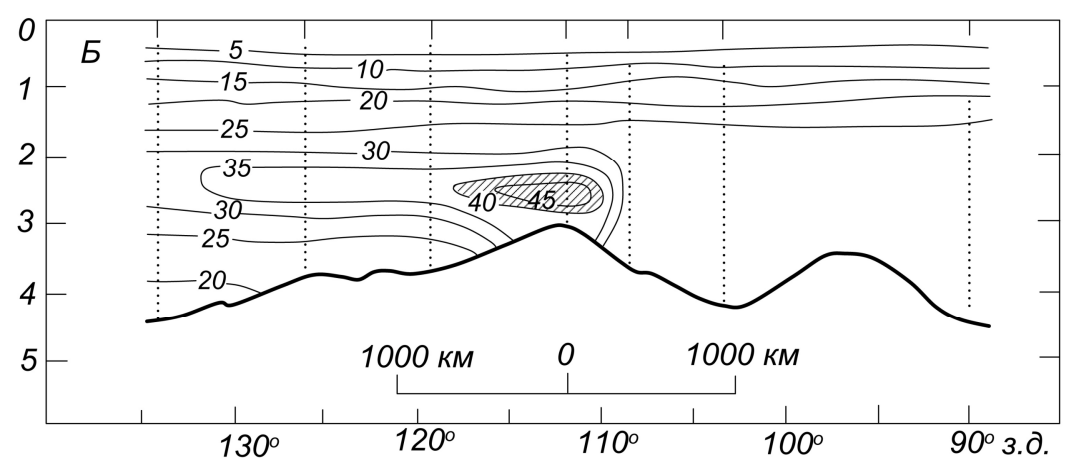

Рис. 6. Ореол распределения легкого изотопа гелия (изолинии $\delta^{3} \mathrm{He}$ ) в водах Тихого океана в районе Восточно-Тихоокеанского поднятия на широте $15^{\circ}$ ю. ш., по данным работ $[8,13]$

На схеме распределения среднегодовых концентраций трития в атмосферных осадках над территорией бывшего СССР максимальная «тритиевая» аномалия наблюдается в районе Восточно-Сибирской платформы [26], будто бы именно в этом районе мог располагаться источник тех- ногенного загрязнения (бомбовый тритий), т.е. южнее границ бывшего СССР на территории Китая (рис. 7). Но это вряд ли возможно, поэтому следует искать другие источники поступления трития в атмосферу над этим регионом. 


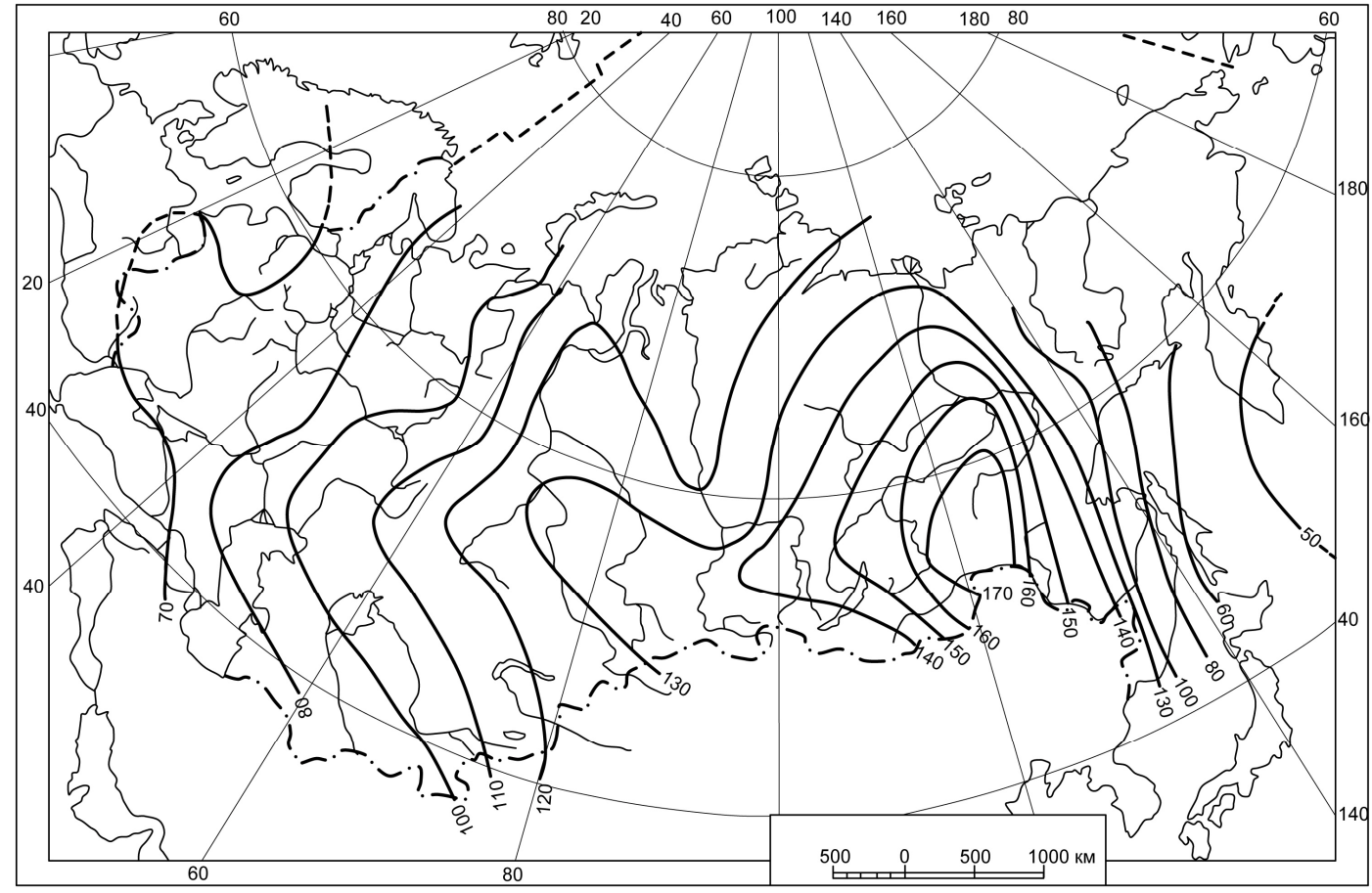

Рис. 7. Распределение среднегодовых конщентраций трития в атмосферных осадках над территорией бывшего СССР за 1979 г. [26]

Мы полагаем, что ими могли быть природные источники. Известно, что в районе Восточно-Сибирской платформы имеется Мировая магнитная аномалия [27], а по данным [26] - огромный суперплюм, который «сформировался в непосредственной близости от ядра» (по выражению Ю.М. Фомина) их образовал «литосферный плюм-вулканоген» (рис. 8).

Именно под воздействием этого суперплюма, по его мнению, образовались так называемые «трубки взрыва», в том числе и кимберлитовые, скопления которых получили название «кимберлитовых полей», и с этой концепцией мы полностью согласны. Вносим лишь небольшую поправку относительно возникновения суперплюма, который представляет собой продукт деятельности природного ядерного реактора Земли, а не просто по неизвестной причине возникает «вблизи от ядра», как считает автор [27].

Основываясь на вышеуказанных фактических данных, мы полагаем, что именно этот суперплюм является источником «поставки» в район аномалии глубинного трития из ядра Земли, постоянно генерирующегося в природном ядерном реактоpe.

Следующим странным на первый взгляд фактом является постоянная в океанической воде величина отношения альфа-активностей изотопов урана $\gamma=$ ${ }^{234} \mathrm{U} /{ }^{238} \mathrm{U}$, равная 1.14 , которое, согласно периодам полураспада указанных изотопов, равным соответственно 250 тыс. лет и 4.5 млрд лет, за сотни миллионов существования океанов уже давно должно было придти к равновесию (т.е. $\gamma=1$ ) благодаря различным периодам полураспада этих изотопов. Это явление можно объяснить только поступлением дополнительных порций легкого изотопа ${ }^{234} \mathrm{U}$ с глубинными водами, в которых, по последним данным [31], величина изотопного сдвига урана может достигать 250 отн. ед. по сравнению с равновесным ураном, в то время как (установлено расчетным путем) в процессе образования ${ }^{234} U$ в результате радиоактивного распада ${ }^{238} \mathrm{U}$ может достигать только 3-4 отн. ед. 


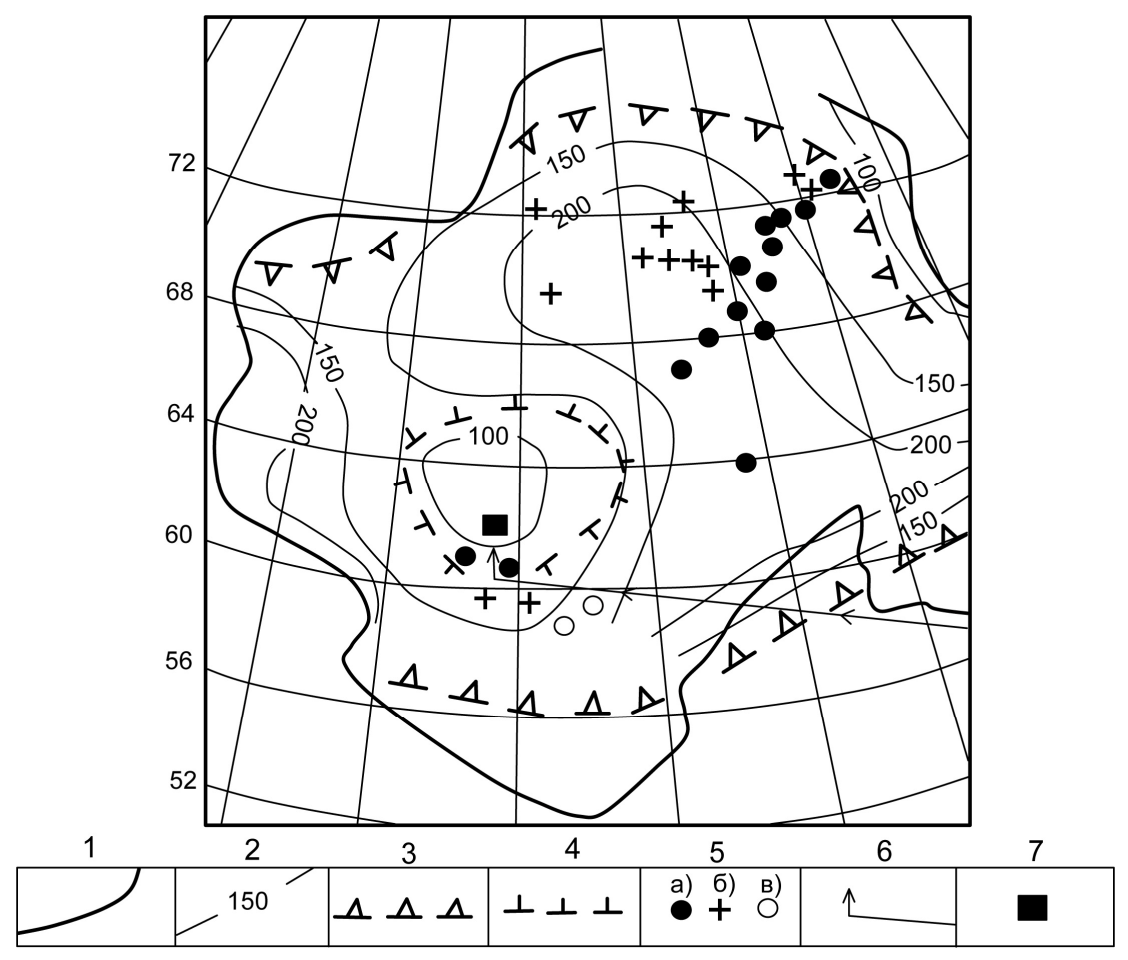

Рис. 8. Восточно-Сибирский платформенный плюм-вулканоген [27]. 1 - граница Сибирской платформы;; 2 - глубина подошвы литосферы, км; 3 - предполагаемая граница литосферного плюм-вупканогена; 4 - предполагаемый контур «жерла» плюм-вулканогена; 5 - кимберлитовые поля установленные: а) палеозойские, б) мезозойские, в) предполагаемые; 6 -траектория полета Тунгусского космического тела; 7 -магнитный (дополнительный) полюс Земли

Сам факт поступления глубинных вод, повышающих величину отношения альфаактивностей ${ }^{234} \mathrm{U} /{ }^{238} \mathrm{U}$, достоверно установлен в настоящее время проведенными нами многочисленными натурными исследованиями изотопного состава урана в подземных водах верхнего гидрогеологического этажа в условиях платформенных и геосинклинальных областей Земли и переходных территорий [18]. Расчеты, проведенные нами с помощью уранизотопного метода определения водного баланса с использованием формулы изотопного разбавления [19], показывают, что наблюдающаяся в океанских водах величина изотопного сдвига урана, равная 1.14 , характеризует смесь около 96\% «теоретических» (т.е. с учетом естественного распада урана) океанских вод с равновесными значениями $\gamma=1$ и 4\% глубинных вод. Полученные по уран-изотопным данным выводы вполне согласуются с известными данными об объемах других типов природных вод. Так, доля подземных вод (возможно, они преимущественно метеогенные, учитывая, что, по мнению современной гидрогеологической науки о подземных водах верхнего гидрогеологического этажа, они образуются в результате фильтрации поверхностных вод) составляет порядка $2-4 \%$, что сопоставимо с погрешностями современных методов определений этого параметра, а суммарный речной сток в океан и испарение почти компенсируются.

Таким образом, приведенный выше анализ имеющейся информации об изотопном составе водорода, кислорода, гелия и урана в океанских и подземных водах показывает, что основным источником происхождения гидросферы Земли являются глубинные воды, поступавшие и продолжающие поступать из земного ядра в виде паров воды в составе ядерных (или мантийных) плюмов, образующихся в результате деятельности природного ядерного реактора в центре планеты и являю- 
щегося основным «силовым генератором» Земли.

Между тем отдельные ученые прошлого столетия обнаруживали признаки существования в недрах планеты не совсем объяснимых в то время явлений. Так, великий русский ученый-энциклопедист В.И. Вернадский [1] еще в 1933 г. первым обратил внимание на грандиозные масштабы выделения ювенильных газов азота, метана, гелия и др. И.Н. Толстихин [24] считает, что отношение ${ }^{3} \mathrm{He} /{ }^{4} \mathrm{He}$ может служить в качестве критерия ювенильности вещества. В работе [28] Ю.А. Шуколюков указывал, что в южной части Тихого океана наблюдается присутствие $\mathrm{He}, \mathrm{Ne}, \mathrm{Ar}, \mathrm{Kr}$ и особенно заметны повышенные значения отношения ${ }^{3} \mathrm{He} /{ }^{4} \mathrm{He}$ в океанских водах, что нельзя объяснить без дополнительного притока гелия-3 из недр Земли. Однако он объясняет это поступлением первичного гелия-3 («солнечного»?), якобы присутствовавшего в составе космического газопылевого вещества и захороненного в центральных частях планеты при ее формировании. Но как же это могло произойти, если гелий очень летуч и постоянно улетучивается из земных недр в космическое пространство и его трудно удержать даже в закрытой стеклянной посуде? Об этом автор умалчивает. Мы же, согласно гипотезе образования Земли, с ядерным реактором в центре [18], повышенные концентрации легкого изотопа гелия в недрах Земли объясняем постоянным распадом трития, образующегося при резко асимметричном делении сверхтяжелых элементов.

В заключение можно отметить, в каких случаях, где и как обнаруживается присутствие глубинных вод в геологических объектах:

- в геодинамических активных зонах $[4,5,30]$, обусловленных современными и новейшими тектоническими движениями, преимущественно в пределах локальных положительных структур;

- в океанских водах с уникальным и стабильным химическим и изотопным составом;
- на участках аномального увеличения изотопного сдвига урана, т.е. отношения альфа-активностей изотопов ${ }^{234} U{ }^{238} \mathrm{U}-$ надежного стабильного индикатора глубинных вод, в водоносных горизонтах верхнего гидрогеологического этажа;

- в месторождениях термальных и минеральных вод, характеризующихся полезными для организма человека химическими элементами глубинного генезиса и смешивающихся с подземными водами верхних водоносных горизонтов;

- в гидротермальных рудных месторождениях;

- на участках загрязнения почвенного покрова тяжелыми металлами в районах поступления на проницаемых участках тектонических нарушений глубинных вод с повышенным содержанием химических элементов глубинного происхождения;

- в геопатогенных зонах аномальных изменений геофизических и геохимических полей в связи с осаждением различных металлов глубинного генезиса вокруг каналов поступления глубинных вод;

- в гидрохимических ореолах алмазоносных районов, особенно на участках алмазоносных кимберлитовых трубок взрыва [21];

- в попутных водах нефтегазовых месторождений.

\section{Библиографический список}

1. Вернадский В.И. Очерки геохимии. М.: Наука, 1989. 442 с.

2. Дерпгольи В.Ф. О водообмене между Землей и мировым пространством // Географич. сб. АН СССР. 1962. Вып. XV. С.199207.

3. Кирюхин В.А., Коротков А.И., Павлов А.Н. Общая гидрогеология. Л.: Недра, 1988. $359 \mathrm{c}$.

4. Копылов И.С. Теоретические и прикладные аспекты учения о геодинамических активных зонах // Современные проблемы науки и образования. 2011. № 4. URL: www.science-education.ru/98-4745.

5. Копылов И.С. Гидрогеологическая роль геодинамических активных зон // Международный журнал прикладных и фунда- 
ментальных исследований. 2014. № 9-3. С. $86-90$.

6. Макинтайр Ф. Почему море соленое // Наука об океане. М.: Прогресс, 1981. С. 137164.

7. Монин А.С. История Земли. Л.: Наука, 1977. $228 \mathrm{c}$.

8. Общая гидрогеология / под ред. Е.В. Пиннекера. Новосибирск: Наука, Сиб. отд-ние, 1980. $231 \mathrm{c.}$

9. Озима М., Подосек $Ф$. Геохимия благородных газов. Л.: Недра, 1987. 343 с.

10. Пиннекер E.B. Проблема формирования подземных концентрированных рассолов // Генезис минеральных и термальных вод. М.: Наука, 1968. С. 64-67.

11. Пиннекер E.B. Проблемы региональной гидрогеологии (Закономерности распределения и формирования подземных вод). М.: Наука, 1977. 186 с.

12. Плотников Н.И. Эксплуатационная разведка подземных вод. М.: Недра, 1979. 272 c.

13. Поиски и разведка подземных вод для целей крупного водоснабжения / сост. Н.Н. Биндеман, А.Т. Бобрышев, Ф.М. Бочевер и др. М.: Недра, 1969. 328 с.

14. Поляк Б.Г. Тепломассопоток из мантии в главных структурах земной коры. М.: Наука, 1988. 192 с.

15. Пронин А.П. Активные глубинные разломы центральной части Русской платформы и их геоэкологическое значение // Геоэкол. исслед. и охр. недр. М., 1994. Вып.3. C.3-11.

16. Сорохтин О.Г. Глобальная эволюция Земли. М.: Недра, 1991. 184 с.

17. Тектоника мантийных струй-плюмов (плюм-тектоника) / URL:www.geomuseum. kuzstu.ru/index.php?option=com_content\&vi ew $=$ article $\&$ id $=23 \&$ Itemid $=23$.

18. Тихонов А.И. Гипотеза об образовании Земли, «необъяснимых» земных явлений и процессов // Глубинная нефть. 2013. Т.1, №8. C.1155-1170.

19. Тихонов А.И. Неравновесный уран в условиях активного водообмена и его использование в геологии и гидрогеологии. Чебоксары, 2009. 458 с.

20. Тихонов А.И., Голищын М.С., Моралев Г.В., Русских А.В. Экспрессный изотопногидрогеохимический метод оценки экологического состояния пресных подземных вод на геологической платформе в условиях широкомасштабного поступления глубинных вод // Ресурсовоспроизводящие, малоотходные и природоохр. технологии освоения недр: матер. конф. М., 2003. C. 296-298.

21. Тихонов А.И., Копылов И.С. Изотопногидрогеохимический метод и перспективы его использования для поисков коренных месторождений алмазов на территории Пермской области // Проблемы минералогии, петрографии и металлогении. Научные чтения памяти П.Н. Чирвинского. 2004. № 7. C. 187-192.

22. Тихонов А.И., Миронова Н.Е., Осипова С.В., Яковлев Е.Ю. Загадочный дейтерий в попутных водах газоконденсатного месторождения // Новината за напреднали наука: матер. конф. Т. 49. География и геология. София: «Бял ГРАД-БГ» ООД, 2013. C. 59-62.

23. Тихонов А.И., Миронова Н.Е., Яковлев Е.Ю., Осипова С.В. Развитие гипотезы образования Астраханского газоконденсатного месторождения в результате поступления мантийного плюма // Отечественная геология. 2014. №3. С. 26-32.

24. Толстихин И.Н. Изотопная геохимия гелия, аргона и редких газов. Л.: Наука, 1986. $200 \mathrm{c}$.

25. Ферронский В.И., Поляков В.А. Изотопия гидросферы Земли. М.: Научный мир, 2009. $632 \mathrm{c}$.

26. Фомин Ю.М. Восточно-Сибирский литосферный плюм-вулканоген / URL: http://www. proza.ru/2011/02/18/1151.

27. Шевнин А.Д. Магнетизм Земли / URL:http://dic.academic.ru/dic.nsf/bse/88657.

28. Шуколюков Ю.А., Левский Л.К. Геохимия и космохимия изотопов благородных газов. М.: Атомиздат, 1972. 336 с.

29. Craig $H$. Isotopic variations in meteoric waters. Science. 1961. Vol. 33. P. 1702-1703.

30. Likutov E.Yu., Kopylov I.S. Complex of methods for studying and estimation of geodynamic activity // Tyumen State University Herald. 2013. № 4. P. 101-106.

31. Yamamoto M., Sato T., Sasaki K., Hama K., Nakamura T., Komura K. Anomalously high ${ }^{234} \mathrm{U} /{ }^{238} \mathrm{U}$ activity ratios of Tatsunokuchi hot spring waters, Ishikawa Prefecture, Yapan. Yournal of Radioanalytical and Nuclear Chemistry. 2003. Vol. 255, N. 2. P. 369-373. 


\title{
The Phenomenon of «Deep Water» Influx from the Earth's Interior and its Role in the Development of the Earth
}

\author{
A.I. Tikhonov ${ }^{\text {a }}$, I.S. Kopylov ${ }^{\text {b }}$ \\ ${ }^{a}$ LTD "SRI geological and geo-environmental problems" (LTD «NIIGiGEP), \\ Akademika Korolyova Str., Bld. 1, Office 13, Cheboksary 428023, Russia \\ E-mail: niigigep@mail.ru \\ ${ }^{\mathrm{b}}$ Natural Sciences Institute of the Perm State University, 4 Genkelya Str., Perm \\ 614990, Russia, E-Mail: georif@yandex.ru
}

The phenomenon of extensive permanent influx of the «deep-water» to the hydrosphere of the Earth characterized by a high content of various chemical components, including mineral and toxic elements of deep origin is considered. Results of analysis of large amount of experimental data suggest that «deep-water» is a source of formation and permanent supplement of the ocean water with stable salinity, chemical and isotopic composition, and the formation of various mineralized water deposits. «Deep-water» can cause formation of sub-standard water clusters within the underground fresh water fields, affecting their ecological quality.

Key words: hydrogeology, deep-water source, evidence of water-kind isotopes, helium, uranium, plumes, nuclear reactor.

\section{References}

1. Vernadskiy V.I., 1989. Ocherki geokhimii [Geochemistry notes]. Moskva, Nauka, p. 442.

2. Derpgolts V.F., 1962. O vodoobmene mezhdu Zemley i mirovym prostranstvom [About water exchange between the Earth and outer space]. Geografich. Sb. AN SSSR. XV: 199 207.

3. Kiryukhin V.A., Korotkov A.I., Pavlov A.N. 1988. Obshchaya gidrogeologiya [Fundamental Hydrogeology]. Leningrad, Nedra, p. 359.

4. Kopylov I.S., 2011. Teoreticheskie i prikladnye aspekty ucheniya o geodinamicheskikh aktivnykh zonakh [Theoretical and practical aspects of doctrine of geodynamic active zones]. Modern problems of science and education. 4. URL: www.scienceeducation.ru/98-4745.

5. Kopylov I.S., 2014. Gidrogeologicheskaya rol geodinamicheskikh aktivnykh zon [Hydrogeological role of geodynamic active zones]. Mezhdunarodnyy zhurnal prikladnykh i fundamentalnykh issledovaniy. 9-3: 86-90.

6. MacIntyre F. 1970 . Why the sea is salt. Scientific American. 223 (5): 104-115.

7. Monin A.S., 1977. Istoriya Zemli [Earth his- tory]. Leningrad, Nauka, p. 228.

8. Obshhaya gidrogeologiya [Fundamental hydrogeology]. Ed. E. V. Pinneker. Novosibirsk, Nauka, Sib. Otd, AN SSSR, 1980, p. 231.

9. Ozima M., Podosek F., 1987. Geokhimiya blagorodnykh gazov [Geochemistry of the noble gases]. Leningrad, Nedra, p. 343.

10. Pinneker E.V., 1968. Problema formirovaniya podzemnykh kontsentrirovannykh rassolov [Problem of formation of concentrated brines]. In Genezis mineralnykh i termalnykh vod. Moskva, Nauka, pp. 64-67.

11. Pinneker E.V., 1977. Problemy regionalnoy gidrogeologii (Zakonomernosti raspredeleniya i formirovaniya podzemnykh vod) [Problems of regional hydrogeology (Regularities of distribution and formation of groundwater)]. Moskva, Nauka, p. 186.

12. Plotnikov N.I., 1979. Ekspluatatsionnaya razvedka podzemnykh vod [Exploitation investigation of groundwater]. Moskva, Nedra, $\mathrm{p}$. 272.

13. Poiski i razvedka podzemnykh vod dlya tseley krupnogo vodosnabzheniya. [Groundwater exploration for large scale water supply] $E d s$. Bindeman N.N., Bobryshev A.T., Bochever F.M. et al. Moskva, Nedra, 1969. p. 328. 
14. Polyak B.G., 1988. Teplomassopotok iz mantii $\mathrm{v}$ glavnykh strukturakh zemnoy kory [Thermal mass flow from mantle in main structures of the Earth crust]. Moskva, Nauka, p. 192.

15. Pronin A.P., 1994. Aktivnye glubinnye razlomy centralnoy chasti Russkoy platformy i ikh geoekologicheskoe znachenie [Active deep faults of central part of the Russian platform and their geological significance]. In Geoekol. issl. i okhr. nedr. 3: 3-11.

16. Sorokhtin O.G. 1991. Globalnaya evolyutsiya Zemli [Global evolution of the Earth]. Moskva, Nedra, p. 184.

17. Tektonika mantiynykh struy-plyumov (plyum-tektonika) [Tectonics of the mantle flow-plumes (plume-tectonics)]. URL: www.geomuseum.kuzstu.ru /index.php?option $=$ com_content\&view $=$ articl e\&id=23\&Itemid $=23$.

18. Tikhonov A.I. 2013. Gipoteza ob obrazovanii Zemli, «neobyasnimykh» zemnykh yavleniy i protsessov [Hypothesis of the Earth formation, "unexplained" terrestrial phenomena, and processes]. Elektronnyy zhurnal «Glubinnaya neft». 1 (8): 1155-1170. URL: http://yournal.deepoil.ru/images/stories/docs/ DO-1-8-2013/5_Tikhonov_1-8-2013.pdf.

19. Tikhonov A.I. 2009. Neravnovesnyy uran v usloviyakh aktivnogo vodoobmena $\mathrm{i}$ ego ispolzovanie $\mathrm{v}$ geologii i gidrogeologii [Nonequilibrium uranium in conditions of active water exchange and its usage in geology and hydrogeology]. Cheboksary, p. 458.

20. Tikhonov A.I., Golitsyn M.S., Moralev G.V., Russkikh A.V. 2003. Ekspressnyy izotopnogidrogeokhimicheskiy metod otsenki ekologicheskogo sostoyaniya presnykh podzemnykh vod na geologicheskoy platforme usloviyakh shirokomasshtabnogo postupleniya glubinnyh vod [Isotope hydrogeochemical method of express assessment of the fresh water ecological condition on geological platform during a large scale inflow of the deep waters]. Mater. Vtor. Mezhdunar. konf. «Resursovosproizvodyashhie, maloothodnye i prirodoohr. tehnologii osvoeniya nedr. Moskva, 15-18 sent. g. M., 2003. S.296-298.

21. Tikhonov A.I., Kopylov I.S. 2004. Izotopnogidrogeokhimicheskiy metod i perspektivy ego ispolzovaniya dlya poiskov korennykh mestorozhdeniy almazov na territorii Permskoy oblasti [Isotope-hydrogeochemical method and its potential of application for primary diamond prospecting on territory of the Perm region]. In Problemy mineralogii, petrografii i metallogenii. Nauchnye chteniya pamyati P.N. Chirvinskogo. 7:187-192.

22. Tihonov A.I., Mironova N.E., Osipova S.V., Yakovlev E.Yu. 2013. Zagadochnyy deyteriy $\mathrm{v}$ poputnykh vodakh gazokondensatnogo mestorozhdeniya [Mysterious deuterium in accompanying water of the gas condensate deposit]. Mat. Za 9-ya mezhd. nauch. prakt. konf. «Novinata za naprednali nauka» Tom. 49. Geografiya i geologiya. Sofiya, Byal GRAD-BG OOD, pp. 59-62.

23. Tikhonov A.I., Mironova N.E., Yakovlev E.Yu., Osipova S.V. 2014. Razvitie gipotezy obrazovaniya Astrakhanskogo gazokondensatnogo mestorozhdeniya $\mathrm{v}$ rezultate postupleniya mantiynogo plyuma [Development of hypothesis of formation of the Astrakhan gas condensate deposit in result of the mantle plume invasion]. Otechestvennaya geologiya. 3: 26-32.

24. Tolstikhin I.N. 1986. Izotopnaya geokhimiya geliya, argona i redkikh gazov [Isotopic geochemistry of helium, argon, and rare gases]. Leningrad, Nauka, p. 200.

25. Ferronskiy V.I., Polyakov V.A. 2009. Izotopiya gidrosfery Zemli [Isotopy of the Earth hydrosphere]. Moskva, Nauchnyy mir, p. 632.

26. Fomin Yu.M. 2011. Vostochno-Sibirskiy litosfernyy plyum-vulkanogen [East-Siberian lithosphere plume-volcanogen]. URL: http://www.proza.ru /2011/02/18/1151.

27. Shevnin A.D. Magnetizm Zemli [Earth magnetism]. URL: http: //dic.academic.ru/ dic.nsf/bse/88657.

28. Shukolyukov Yu.A., Levskiy L.K. 1972. Geokhimiya i kosmokhimiya izotopov blagorodnykh gazov [Geochemistry and cosmochemistry of isotopes of noble gases].. Moskva, Atomizdat, p. 336.

29. Craig, H. 1961. Isotopic variations in meteoric waters. Science. 33: 1702-1703.

30. Likutov E.Yu., Kopylov I.S. 2013. Complex of methods for studying and estimation of geodynamic activity. Tyumen State University Herald. 4: 101-106.

31. Yamamoto M., Sato T., Sasaki K., Hama K. Nakamura T., and Komura K. 2003. Anomalously high ${ }^{234} \mathrm{U} /{ }^{238} \mathrm{U}$ activity ratios of Tatsunokuchi hot spring waters, Ishikawa Prefecture, Yapan. Yournal of Radioanalytical and Nuclear Chemistry. 255 (2): 369-373. 